\title{
Variability Over Time of Normal-Sized Fetal Renal Pelvis During the Second Trimester Scan
}

\section{(우(1) $(8) \ominus$}

\author{
Authors
}

Maria Aurora Hernandez Røset ${ }^{1,2}$, Harm-Gerd Karl Blaas ${ }^{1,2}$, Tove Anita Fagerli ${ }^{1}$, Torbjørn Moe Eggebø ${ }^{1,2}$

\section{ABSTRACT} ity of measurements.
Purpose To investigate the variability of the normal-sized fetal renal pelvis ( $\leq 5 \mathrm{~mm}$ ) over time and to analyze repeatabil-

Materials and Methods 98 fetal renal pelvises and 49 fetal urinary bladders were analyzed at a gestational age of 17-20 weeks at St. Olavs Hospital, Trondheim, Norway. The anterior-posterior diameter (APD) of the fetal renal pelvis and two diameters of the fetal bladder were measured with an interval of at least $30 \mathrm{~min}$. Intra- and interobserver variations and variations over time and in association with bladder size were investigated.

Results The mean difference in renal pelvis size between the first and second measurements was $0.09 \mathrm{~mm}(95 \% \mathrm{Cl},-0.09$ to $0.26 \mathrm{~mm}$ ). The variation over time was $\leq 1 \mathrm{~mm}$ in $85 \%$ of cases and the renal pelvis was $\leq 4 \mathrm{~mm}$ in both the first and second examinations in $92 \%$ of cases. The intraclass correlation coefficient (ICC) was 0.54 (95\% Cl: 0.31 to 0.69 ). We did not observe any association between variation of bladder size and variation of APD. The difference in fetal renal pelvis size was $\leq 1 \mathrm{~mm}$ in $70 \%$ of observations for the first examiner and $58 \%$ for the second examiner. The intraobserver ICCs were 0.71 (95\% Cl: 0.62-0.78) and 0.60 (95\% Cl: 0.50-0.70) for the two observers respectively. The interobserver difference was $\leq 1 \mathrm{~mm}$ in $72 \%$ of cases and the interobserver ICC was 0.56 (95\% Cl: 0.34-0.71).

Conclusion The variation of the APD of the fetal renal pelvis over time was small in fetuses with the APD in the lower range and can mainly be explained by intraobserver variation.

\section{Abbreviations}

APD anterior-posterior diameter

ICC intraclass correlation coefficient

$\mathrm{Cl} \quad$ confidence interval

SD standard deviation

\section{Introduction}

Fetal pyelectasis is the most common prenatally diagnosed condition occurring in $1-5 \%$ of all pregnancies [1-3]. Fetal renal pelvic dilatation is commonly observed during prenatal ultrasound examinations, and there is broad agreement that there is a relationship between pyelectasis observed prenatally and the possibility for postnatal intervention for hydronephrosis. Mild hydronephrosis in the second trimester is also a soft marker for trisomy 21 [4]. Various cut-off values for dilatation of the fetal renal pelvis are being described as requiring postnatal investigations [5-10]. Although clear limits of delineation for hydronephrosis have yet to be defined, it is generally accepted that the more severe the renal pelvis dilatation, the more likely postnatal intervention will be warranted [11]. The single most widely used parameter to assess renal pelvis dilatation in prenatal diagnosis is the anterior-posterior diameter (APD) [12]. Published charts showing the size of the fetal renal pelvis during pregnancy are available. The chart published by Chitty 
and Altman suggests linear growth [13] while that of Van Vureen et al. showed a curvilinear relationship with a narrower range [14]. It is important to establish accuracy in the measurement of this parameter before any limits for cut-off values can be set.

It has been reported that the size of the renal pelvis varies considerably over time during routine ultrasound examination. The observed variation might be associated with variation in urine production and urinary bladder size but is also influenced by intra- and interobserver variation $[15,16]$. The importance of the observed variation needs to be investigated. The aim of the study was to investigate the variability over time of fetal renal pelvises in the lower range and to analyze the repeatability of measurements.

\section{Materials and Methods}

From October 2014 to May 2015, a prospective observational study was conducted at the National Center for Fetal Medicine, St. Olavs Hospital in Trondheim, Norway with 51 fetuses with renal pelvises in the lower range seen during routine ultrasound scan in the second trimester. Fetuses with at least one renal pelvis $>5 \mathrm{~mm}$ were not included.

All ultrasound scans were performed by one fetal medicine specialist and one midwife specialized in fetal ultrasonography. Both are experienced ultrasound operators with more than 10 years of experience. All examinations were done using the same ultrasound device, a Voluson E-8, (GE Medical Systems, Zipf, Austria), with a 3.5-7.5-MHz 3D curved multifrequency transabdominal transducer.

The first examiner measured the maximum APD of both the right and left fetal kidneys in no particular order. Immediately afterwards, the second examiner measured the APD of both fetal kidneys also in no particular order. The second examiner, a midwife, then performed the routine fetal scan after which the first examiner repeated all of the measurements at least 30 min from the first time the APD diameters were measured. Both examiners measured the renal pelvises in each fetus only when the spine was positioned anteriorly or posteriorly.

The measurements of the maximum APD diameters were performed using a standard method. The fetal kidneys were identified in a transverse scan and the greatest APD diameters were searched by scrolling in depth. The APD diameter was measured transverse to the fetal spine as shown on the left image in > Fig. 1. The image was zoomed in when the examiner found the placement of calipers to be difficult. Three replicate measurements of the maximum APD diameters of the fetal kidneys on both sides were taken by the examiners in each patient with every measurement for each side taken from a new image. The measurement results on the ultrasound screen were covered by colored opaque paper. The two examiners were not present during each other's examination and were kept unaware of their own as well as each other's results until after the entire study was completed. The first examiner also measured the length and width of the fetal bladder in the frontal plane as shown on the right image in $\mathbf{F i g .} \mathbf{1}$ at the end of each of her two scanning sessions, which were at least 30 min apart, and the mean values were used in the analyses. A 3D acquisition of the fetal bladder was recorded in the first session and the volume was calculated using the Virtual Organ Computer-aided Analysis (VOCAL) technique as illustrated in > Fig. 2 [17].

\section{Statistical analyses}

Normality plots were used to assess the distribution of obtained measurements. Intraobserver repeatability of the measurements was expressed as the difference between the highest and lowest measurements, the intraclass correlation coefficient (ICC) and the repeatability coefficient. The repeatability coefficient defines the range within which two measurements by the same observer will fall for $95 \%$ of subjects. The differences between the first, second and third measurements were evaluated with three-way analysis of variance.

The analyses of interobserver agreement and variation over time were performed using the mean of three measurements. If zero was inside the $95 \% \mathrm{Cl}$ of the difference, no bias was assumed. To assess systematic bias, differences between values were plotted against means of the measurements. Limits of agreement with $95 \%$ Cls of the lower and upper limits were calculated as described by Bland and Altman [18]. Interobserver agreement and variation over time were also expressed using the two-way random effects ICC. Associations between the size of the renal pelvis with variation over time and bladder size were investigated using linear regression analysis and Pearson correlation coefficient. Statistical analyses were performed using the statistical software package SPSS statistics version 21.0 (IBM SPSS, Armonk, NY, USA). P-values < 0.05 were considered significant.

\section{Results}

Two of 51 cases were excluded because of fetal anomalies. The study population comprised 49 fetuses with a total of 98 fetal kidneys and 49 fetal urinary bladders. Each kidney is regarded as a single case. The mean APD was $2.6 \mathrm{~mm}$ for the right kidney and $2.5 \mathrm{~mm}$ for the left $(p=0.6)$. The median maternal age was 31 years (range 22 to 42), $42 \%$ were nulliparous women and the median gestational age was 18 weeks (range 17 to 20 weeks). The intraobserver repeatability of measurements of the fetal renal pelvis for the two examiners is presented in $>$ Table 1 . The mean values for the first, second and third measurements were 2.5, 2.6 and $2.6 \mathrm{~mm}$ for the first examiner vs. 2.5, 2.4 and $2.6 \mathrm{~mm}$ for the second examiner. Three-way analysis of variance revealed no systematic differences between the first, second or third measurements for both examiners ( $p=0.37$ vs. $p=0.33$ ) and the largest differences did not vary in any systematic way over the range of values measured for any of the examiners. The largest difference was $\leq 1 \mathrm{~mm}$ in $70 \%$ of observations for the first examiner and $58 \%$ for the second. The ICC was 0.71 ( $95 \% \mathrm{Cl}: 0.62$ to 0.78$)$ and 0.60 ( $95 \% \mathrm{Cl}: 0.50$ to 0.70$)$ for the two observers respectively.

The interobserver agreement between the two examiners in measuring the fetal renal pelvis is presented in $>$ Table 2 . The variation was $>2 \mathrm{~mm}$ in five cases ( $>$ Fig. 3 ) and the difference was $\leq 1 \mathrm{~mm}$ in $72 \%$ of cases. The mean difference was $0.11 \mathrm{~mm}$ ( $95 \% \mathrm{Cl}:-0.09$ to $0.31 \mathrm{~mm}$ ). Zero was included within the $\mathrm{Cl}$ interval indicating no systematic bias. The mean difference showed normal distribution. The limits of agreement with $95 \% \mathrm{Cl}$ are presented in > Table 2 and illustrated in > Fig. 3. There was a tendency for higher variation at increasing values. The ICC was $0.56(95 \% \mathrm{Cl}$ : $0.34-0.71)$. Both examiners measured the fetal renal pelvis 

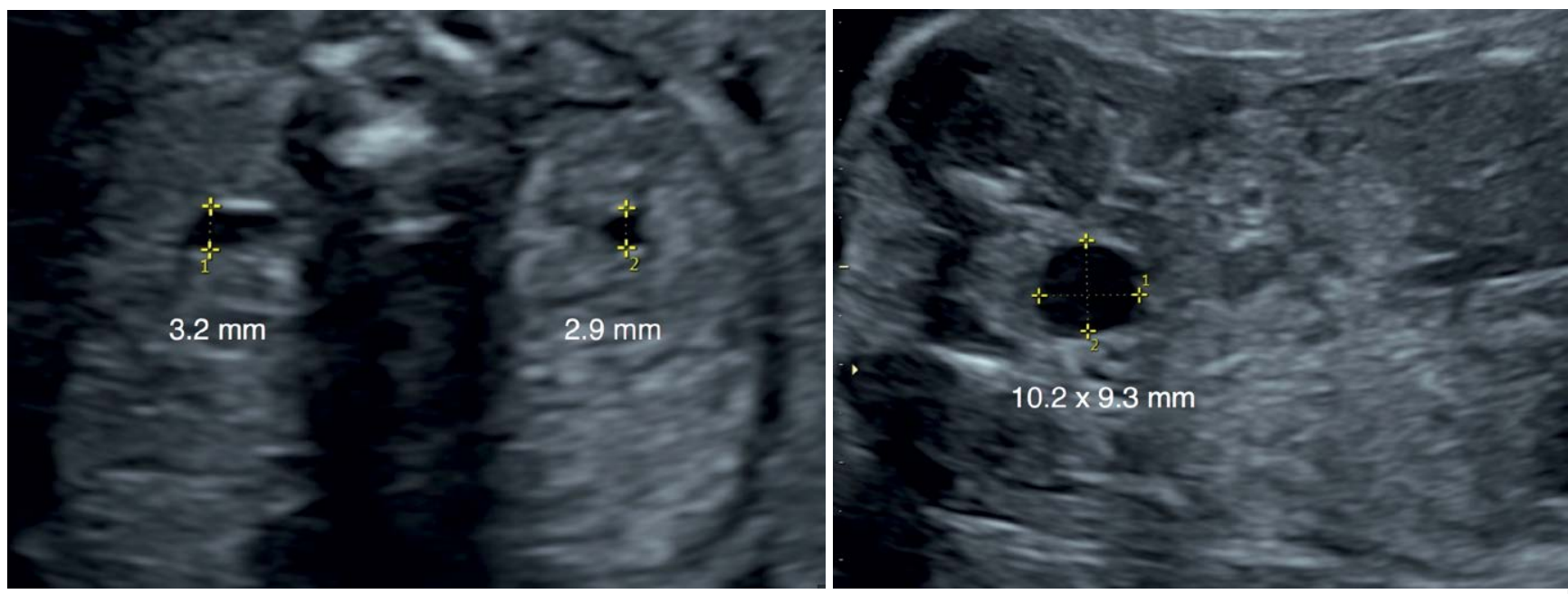

- Fig. 1 Measurements of the anterior-posterior diameter of the fetal renal pelvises (left image) and two diameters of the bladder in the frontal plane (right image).
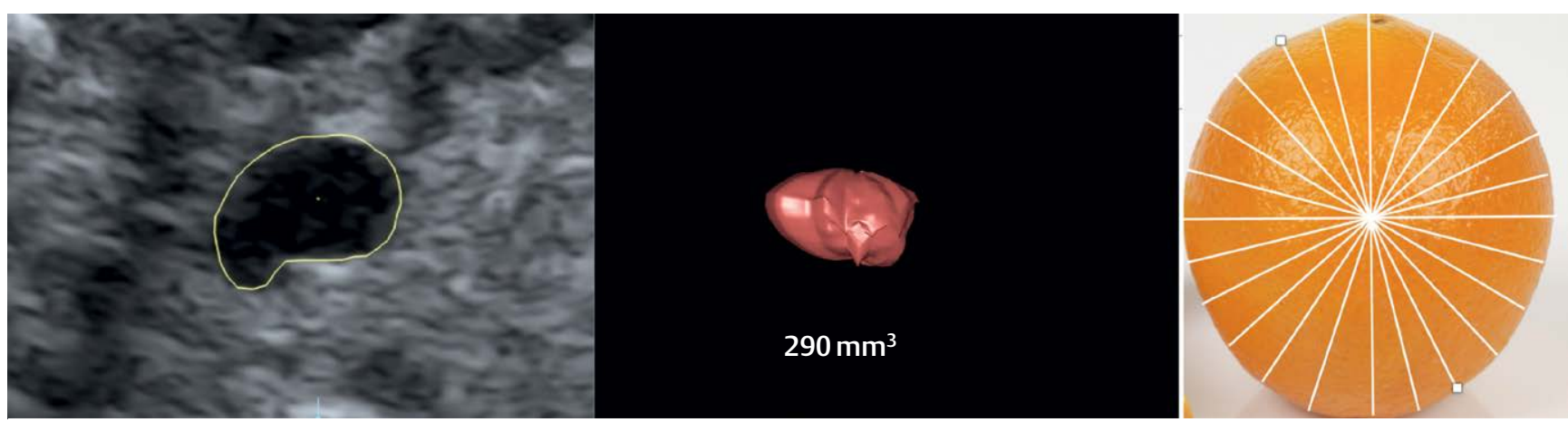

- Fig. 2 Illustration of Virtual Organ Computer-aided Analysis (VOCAL). The volume was calculated from 12 sections of the bladder rotated as illustrated on the orange fruit.

- Table 1 Intraobserver repeatability of anterior-posterior diameter of fetal renal pelvis.

\begin{tabular}{|c|c|c|c|c|c|c|c|c|c|c|}
\hline \multirow[b]{2}{*}{ Measurement } & \multirow[b]{2}{*}{ Mean } & \multirow[b]{2}{*}{ Median } & \multirow[b]{2}{*}{ Range } & \multirow[b]{2}{*}{ ICC (95\% Cl) } & \multirow[b]{2}{*}{$\begin{array}{c}\text { Repeatability } \\
\text { coefficient }\end{array}$} & \multicolumn{5}{|c|}{ Difference between highest and lowest values } \\
\hline & & & & & & Mean & Median & $\begin{array}{c}\text { 10th } \\
\text { percentile }\end{array}$ & $\begin{array}{c}\text { 90th } \\
\text { percentile }\end{array}$ & Range \\
\hline Examiner 1 & 2.6 & 2.5 & $1.3-5.8$ & $0.71(0.62-0.78)$ & $+\mid-1.33$ & 0.85 & 0.70 & 0.30 & 1.60 & 0.1 to 3.2 \\
\hline Examiner 2 & 2.5 & 2.2 & $0.8-4.9$ & $0.60(0.50-0.70)$ & $+\mid-1.80$ & 1.10 & 0.95 & 0.30 & 1.91 & 0 to 3.9 \\
\hline
\end{tabular}

Mean, median and range of measurements are calculated from the mean of three measurements. ICC: intraclass correlation coefficient

as $\leq 4 \mathrm{~mm}$ in $91 / 98$ (93\%) of the cases and they agreed in $86 / 98$ ( $88 \%)$ of the cases using this cut-off level.

The variation over time in measuring the fetal renal pelvis is presented in $>$ Table 2 . The variation was $>2 \mathrm{~mm}$ in three cases ( $\triangleright$ Fig. 4) and the difference was $\leq 1 \mathrm{~mm}$ in $85 \%$ of cases. The mean difference was $0.09 \mathrm{~mm}$ and zero was included in the $\mathrm{Cl}$ interval ( $95 \% \mathrm{Cl}:-0.09$ to $0.26 \mathrm{~mm}$ ). The mean difference showed normal distribution. There was no systematic variation over the range of measured values, and the limits of agreement with $95 \% \mathrm{Cl}$ are presented in > Table 2 and illustrated in > Fig. 4. The ICC was $0.54(95 \%$ $\mathrm{Cl} 0.31$ to 0.69$)$. The fetal renal pelvis was $\leq 4 \mathrm{~mm}$ in both the first and second examination in 90/98 (92\%) of the cases. We did not find any significant difference in the size of the fetal renal pelvis related to sex. The mean APD in boys was $2.5 \mathrm{~mm}$ vs. $2.6 \mathrm{~mm}$ in girls $(p=0.67)$. 

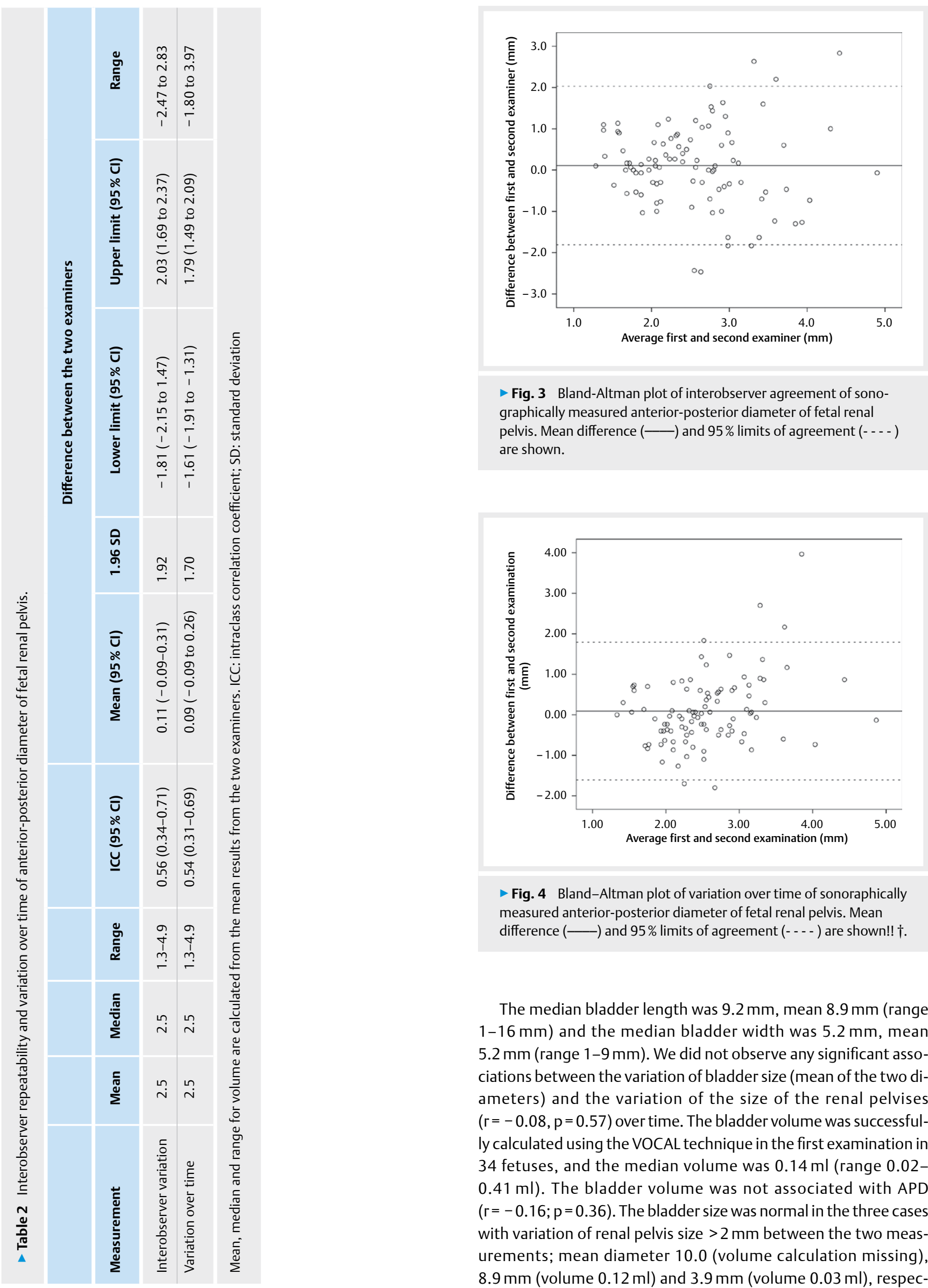

- Fig. 3 Bland-Altman plot of interobserver agreement of sonographically measured anterior-posterior diameter of fetal renal pelvis. Mean difference (-) and $95 \%$ limits of agreement (- - - - ) are shown.

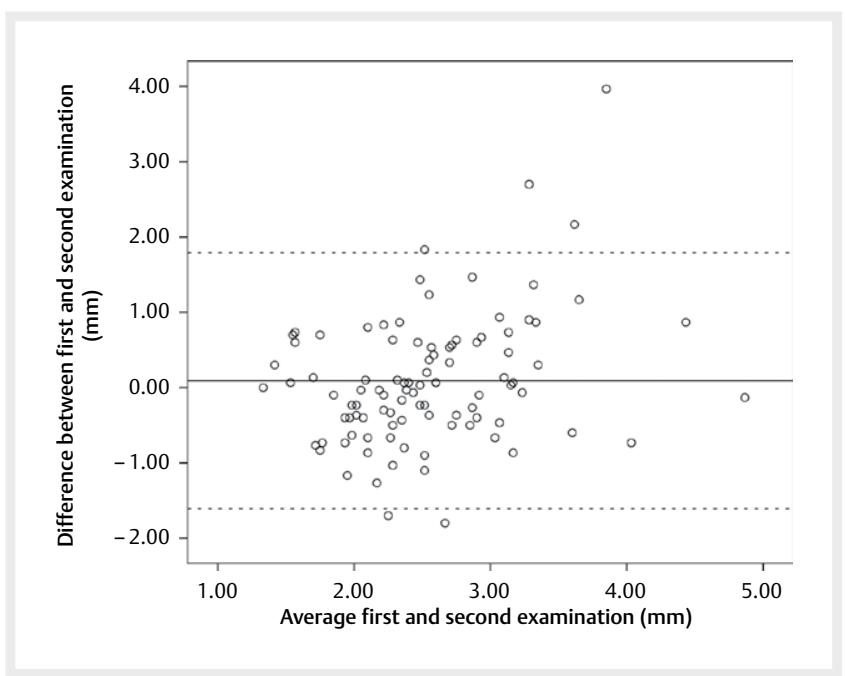

- Fig. 4 Bland-Altman plot of variation over time of sonoraphically measured anterior-posterior diameter of fetal renal pelvis. Mean difference (- - and $95 \%$ limits of agreement (- - - ) are shown!! †.

The median bladder length was $9.2 \mathrm{~mm}$, mean $8.9 \mathrm{~mm}$ (range $1-16 \mathrm{~mm}$ ) and the median bladder width was $5.2 \mathrm{~mm}$, mean $5.2 \mathrm{~mm}$ (range 1-9 mm). We did not observe any significant associations between the variation of bladder size (mean of the two diameters) and the variation of the size of the renal pelvises $(r=-0.08, p=0.57)$ over time. The bladder volume was successfully calculated using the VOCAL technique in the first examination in 34 fetuses, and the median volume was $0.14 \mathrm{ml}$ (range $0.02-$ $0.41 \mathrm{ml}$ ). The bladder volume was not associated with APD $(r=-0.16 ; p=0.36)$. The bladder size was normal in the three cases with variation of renal pelvis size $>2 \mathrm{~mm}$ between the two measurements; mean diameter 10.0 (volume calculation missing), $8.9 \mathrm{~mm}$ (volume $0.12 \mathrm{ml}$ ) and $3.9 \mathrm{~mm}$ (volume $0.03 \mathrm{ml}$ ), respec- 
tively. The bladder size was also normal in the five cases with variation $>2 \mathrm{~mm}$ between examiners. All fetuses including those with variation over time and interobserver variation $>2 \mathrm{~mm}$ had uncomplicated follow-up in the perinatal period.

\section{Discussion}

The main finding in our study was slight variation in the size of the fetal renal pelvis over time, but the size of the fetal renal pelvis was $\leq 4 \mathrm{~mm}$ in both examinations in $92 \%$ of cases and the variation was $>2 \mathrm{~mm}$ in only three cases. The observed variation was not associated with the variation in bladder size and can mainly be explained by intraobserver variation. We think that repeated measurements over time are not necessary in fetuses with a renal pelvis in the lower range.

The APD of the fetal renal pelvis measured by ultrasound is the most commonly utilized measurement for the evaluation and monitoring of possible upper urinary tract obstruction. The threshold values which can be reliably used to identify cases which merit follow-up examination prenatally because of the likelihood of developing hydronephrosis are still being discussed. The second trimester scan is recommended in pregnancy week 17-20 in Norway, whereas other countries routinely perform a later second trimester scan. The size of fetal renal pelvis is probably smaller early as compared to later in the second trimester, but the same threshold of four to five $\mathrm{mm}$ is recommended in both periods $(3,7)$. Corteville et al. proposed a minimum cut-off of four millimeters before 33 weeks of gestation and seven millimeters afterwards to identify those needing postnatal follow-up [7]. In a later study, Sairam et al. concluded that an APD of the fetal renal pelvis $\geq 7 \mathrm{~mm}$ signifies moderate to severe hydronephrosis and anything less than this is mild and invariably has a good prognosis [3]. On the other hand, Duin et al. concluded in a study involving 764 fetuses with hydronephrosis that a cut-off APD of the fetal renal pelvis $\geq 5 \mathrm{~mm}$ in the second and/or third trimester of pregnancy enables better detection of patients with uropathies and indication for surgery [19]. One major aim of the second trimester routine scan is to identify the fetuses that might need postnatal evaluation and intervention in order to avoid complications. On the other hand, it is also important not to include too many false-positive cases entailing avoidable anxiety and unnecessary follow-up scans later in pregnancy.

A reliable method for measuring the size of the fetal renal pelvis is important. Pereira et al. performed repeatability analyses in fetuses with mild hydronephrosis and found that inter- and intraobserver APD measurement errors were low [20]. The Bland Altman plot of interobserver variation in their study was similar to the variation observed in our study ( $\triangleright$ Fig. 3 ). We found a stable variation over the range of values and the difference between the two examiners $\leq 1 \mathrm{~mm}$ in $72 \%$ of measurements. The intraobserver and interobserver ICCs showed only moderate to low repeatability. It is difficult to measure small structures exactly and a difference from 2 to $2.5 \mathrm{~mm}$ represents a $25 \%$ variation. We, therefore think that the low ICCs have little clinical importance.

Persutte et al. examined 20 fetuses with mild pyelectasis (APD $\geq 4 \mathrm{~mm}$ and $<10 \mathrm{~mm}$ ) and found a substantial variation of the size of the renal pelvis leading them to question whether one meas- urement during a routine second trimester scan is enough. They also found that increasing dilatation was positively associated with increasing bladder dilatation in eight fetuses [15] and that this association might be explained by reflux. In another study by Robinson et al. investigating 13 fetuses with pyelectasis, there was no significant change in the APD of the fetal renal pelvis with a full or empty bladder, but they found a significant increase in the size of the fetal renal APD after maternal hydration [21]. We observed a low variation in the size of the renal pelvis over time as illustrated in Fig. 4. The variation was $\leq 1 \mathrm{~mm}$ in $85 \%$ of cases. We did not observe any association between renal pelvis size and bladder filling among fetuses with a renal pelvis in the lower range $(<5 \mathrm{~mm})$ with a low probability of reflux.

The strengths of the study are the performance of all examinations by experienced operators who were not aware of each other's measurements and the avoidance of bias due to repeated measurements by covering the ultrasound screen with opaque tape.

The limitations are related to the small study population, although the size of the study population is in accordance with other repeatability studies [20,22]. Limits of agreement are calculated as $+/$ - 2 standard deviations of the mean difference between observers or observations, and only their $\mathrm{Cl}$ intervals are related to the number of inclusions. We included only fetuses with renal pelvises in the lower range. The clinical importance might be more significant in fetuses with pyelectasis. However, fetuses with pyelectasis and mild hydronephrosis are investigated in other studies. The lack of information on maternal hydration status is a limitation of the study. The echogenicity of the renal parenchyma was not described when deemed normal and the thickness of the bladder wall was not measured. Since it was not the aim of this study to compare fetal measurements with measurements in the newborn, the size of the renal pelvis after delivery was not measured.

We conclude that variation of the APD of the fetal renal pelvis over time is small in fetuses with an APD size in the lower range.

\section{Conflict of Interest}

The authors declare that they have no conflict of interest.

\section{References}

[1] Scott JE, Renwick M. Urological anomalies in the Northern Region Fetal Abnormality Survey. Arch Dis Child. 1993; 68: 22-26

[2] Livera LN, Brookfield DS, Egginton JA, Hawnaur JM. Antenatal ultrasonography to detect fetal renal abnormalities: A prospective screening programme. BMJ 1989; 298: 1421-1423

[3] Sairam S, Al-Habib A, Sasson S, Thilaganathan B. Natural history of fetal hydronephrosis diagnosed on mid-trimester ultrasound. Ultrasound Obstet Gynecol. 2001; 17: 191-196

[4] Agathokleous M, Chaveeva P, Poon LC, Kosinski P, Nicolaides KH. Meta-analysis of second-trimester markers for trisomy 21. Ultrasound Obstet Gynecol. 2013; 41: 247-261

[5] Cohen-Overbeek TE, Wijngaard-Boom P, Ursem NT, Hop WC, Wladimiroff JW, Wolffenbuttel KP. Mild renal pyelectasis in the second trimester: Determination of cut-off levels for postnatal referral. Ultrasound Obstet Gynecol. 2005; 25: 378-383 
[6] Coplen DE, Austin PF, Yan Y, Blanco VM, Dicke JM. The magnitude of fetal renal pelvic dilatation can identify obstructive postnatal hydronephrosis, and direct postnatal evaluation and management. J Urol. 2006; 176: 724-727 discussion 727

[7] Corteville JE, Gray DL, Crane JP. Congenital hydronephrosis: correlation of fetal ultrasonographic findings with infant outcome. Am J Obstet Gynecol. 1991; 165: 384-388

[8] Ouzounian JG, Castro MA, Fresquez M, al-Sulyman OM, Kovacs BW. Prognostic significance of antenatally detected fetal pyelectasis. Ultrasound Obstet Gynecol. 1996; 7: 424-428

[9] Siemens DR, Prouse KA, MacNeily AE, Sauerbrei EE. Antenatal hydronephrosis: Thresholds of renal pelvic diameter to predict insignificant postnatal pelviectasis. Tech Urol 1998; 4: 198-201

[10] Wollenberg A, Neuhaus T], Willi UV, Wisser J. Outcome of fetal renal pelvic dilatation diagnosed during the third trimester. Ultrasound Obstet Gynecol. 2005; 25: 483-488

[11] Ismaili K, Hall M, Piepsz A, Alexander M, Schulman C, Avni FE. Insights into the pathogenesis and natural history of fetuses with renal pelvis dilatation. Eur Urol. 2005; 48: 207-214

[12] Gramellini D, Fieni S, Caforio E, Benassi G, Bedocchi L, Beseghi U et al. Diagnostic accuracy of fetal renal pelvis anteroposterior diameter as a predictor of significant postnatal nephrouropathy: Second versus third trimester of pregnancy. Am J Obstet Gynecol. 2006; 194: 167-173

[13] Chitty LS, Altman DG. Charts of fetal size: Kidney and renal pelvis measurements. Prenat Diagn. 2003; 23: 891-897

[14] van Vuuren SH, Damen-Elias HA, Stigter RH, van der Doef R, Goldschmeding R, de Jong TP et al. Size and volume charts of fetal kidney, renal pelvis and adrenal gland. Ultrasound Obstet Gynecol. 2012; 40: 659-664
[15] Persutte WH, Hussey M, Chyu J, Hobbins JC. Striking findings concerning the variability in the measurement of the fetal renal collecting system. Ultrasound Obstet Gynecol. 2000; 15: 186-190

[16] Damen-Elias HA, Stigter RH, De Jong TP, Visser GH. Variability in dilatation of the fetal renal pelvis during a bladder filling cycle. Ultrasound Obstet Gynecol. 2004; 24: 750-755

[17] Kusanovic JP, Nien JK, Goncalves LF, Espinoza J, Lee W, Balasubramaniam $\mathrm{M}$ et al. The use of inversion mode and 3D manual segmentation in volume measurement of fetal fluid-filled structures: Comparison with Virtual Organ Computer-aided AnaLysis (VOCAL). Ultrasound Obstet Gynecol. 2008; 31: 177-186

[18] Bland JM, Altman DG. Applying the right statistics: Analyses of measurement studies. Ultrasound Obstet Gynecol. 2003; 22: 85-93

[19] Duin LK, Willekes C, Koster-Kamphuis L, Offermans J, Nijhuis JG. Fetal hydronephrosis: Does adding an extra parameter improve detection of neonatal uropathies? J Matern Fetal Neonatal Med 2012; 25: 920-923

[20] Pereira AK, Reis ZS, Bouzada MC, de Oliveira EA, Osanan G, Cabral AC. Antenatal ultrasonographic anteroposterior renal pelvis diameter measurement: Is it a reliable way of defining fetal hydronephrosis? Obstet Gynecol Int 2011; 2011: 861865

[21] Robinson JN, Tice K, Kolm P, Abuhamad AZ. Effect of maternal hydration on fetal renal pyelectasis. Obstet Gynecol. 1998; 92: 137-141

[22] Valentin L, Bergelin I. Intra- and interobserver reproducibility of ultrasound measurements of cervical length and width in the second and third trimesters of pregnancy. Ultrasound Obstet Gynecol. 2002; 20: $256-262$ 